\title{
Barrier Membrane, a Device for Regeneration: Properties and Applications
}

\author{
Sara Soheilifar ${ }^{1}$; Sepideh Soheilifar ${ }^{2, *}$; Mohsen Bidgoli ${ }^{1}$; Parviz Torkzaban ${ }^{1}$ \\ ${ }^{1}$ Department of Periodontology, Hamadan University of Medical Sciences, Hamadan, IR Iran \\ ${ }^{2}$ Department of Orthodontics, Shahid Beheshti University of Medical Sciences, Tehran, IR Iran \\ ${ }^{*}$ Corresponding author: Sepideh Soheilifar, Department of Orthodontics, Shahid Beheshti University of Medical Sciences, Evin St., Tehran, IR Iran. Tel: +98-9121944033, E-mail: \\ se.soheilifar@gmail.com
}

Received: June 18, 2014; Revised: July 16, 2014; Accepted: July 19, 2014

\begin{abstract}
Context: This article reviews the available evidence about the barrier membranes utilized in Guided Tissue Regeneration process to prevent the migration of unfavorable cells to the wound area.

Evidence Acquisition: Available evidence about membranes properties and their different uses were reviewed, and the results of clinical and animal studies and systematic reviews were gathered.

Results: A large number of existing membranes with different features and compositions may lead to different study results; none of the available membranes can result in $\% 100$ predictable outcomes.

Conclusions: Effectiveness of membranes in treating intrabony defects is very controversial; however, treating furcation defects using membranes was reported to be successful in a large number of studies.
\end{abstract}

Keywords:Barrier; Bioabsorbable; Nonabsorbable; Membranes, Artificial; Guided Tissue Regeneration; Bone Regeneration

\section{Context}

This article reviews the available evidence about the barrier membranes utilized in Guided Tissue Regeneration process to prevent the migration of unfavorable cells to the wound area.

\section{Evidence Acquisition}

Available evidence about membranes' properties and their different applications were reviewed, and the results of clinical and animal studies and systematic reviews were gathered. The reviewed articles were published from 1982 to 2013.

The reconstruction of large tissue defects presents a challeng to surgical community. In oral cavity, these defects may be the result of trauma, tumor resection or infection (e.g. periodontal defects) (1). The perceived need of the surgeons to rehabilitate the patient has led to the introduction of many regeneration methods (2). Of them, two widely accepted methods are Guided Tissue Regeneration (GTR) and Guided Bone Regeneration (GBR).

GTR process includes the placement of a physical barrier to populate the periodontitis-affected root surface with periodontal ligament cells and inhibit the migration of other cells $(3,4)$. The mechanism of GBR is the same as GTR, and the barrier membrane prevents epithelial and fibrous tissue migration and allows bone formation within the clot beneath the membrane (5). However, the two techniques have some differences, mainly the fact that wounds treated by GTR have an open connection with the oral cavity by the means of gingival sulcus predisposes the area to microorganism penetration (1). This article aimed to address applications of barrier membranes and their roles in tissue regeneration.

\subsection{Barrier Membrane Properties}

Based on many studies, it was concluded that a barrier membrane with a favorable function has to meet certain important design criteria, including:

- The material should be "biocompatible". It should not stimulate the immune system or produce sensitization that may interfere with wound healing. However, it should be noted that no material can be \%100 inert and in some situations tissue reactions may be seen.

- To inhibit migration of unwanted cells to the material, the membrane should act as a "barrier". This barrier, however, would allow the passage of nutrients and gases.

- Another important property of a barrier material is "Tissue Integration". This property inhibits rapid epithelial migration on the outer surface of the material or encapsulation of the material.

- Ability to "create and maintain a space" adjacent to the root surface is another essential property. This property allows the cells from the periodontal ligament to enter into the space.

- The membrane should have a design that is "easy to trim and adjust to the desired site". Easy manipulation may affect the predictability of clinical outcome (6). 


\subsection{Non-Absorbale Barrier Membranes}

The initial membranes were nonabsorbable and required a second surgery to be removed. In 1980s, during the first attempts to regenerate tissue through GTR, a bacterial filter made from cellulose acetate (Millipore ${ }^{\circledR}$ ) was introduced as a barrier membrane. This membrane resulted in regeneration of cementum, alveolar bone and periodontal ligament in experimental animal studies (7). Later studies have utilized membranes of expanded polytetrafluoroethylene (ePTFE). The basic molecule of this material is a polymer composed of a carbon-carbon bond with four attached fluorine atoms. The material neither interfere with the wound healing, nor stimulate any distinct tissue reaction in the body and has been used relatively successfully in many animal and clinical studies (6). One of the complications of this membrane is its exposure to the oral cavity which may result in bacterial infection and deterioration of wound healing (8). Donos et al. reported that membrane exposure would have an adverse effect on the regeneration process and may stop the treatment (9). Besides, Rasmusson et al. which have used combined use of the material over autologous bone graft in order to regenerate bone defects in rabbits, have concluded that membranes would be effective, as long as they are in place, and after membrane removal, considerable graft resorption would minimize the successfulness of regenerative surgery (10). Despite controversial results regarding the effectiveness of ePTFE membrane, the membrane is still the best documented material and considered as a gold standard, which all other introduced membranes should be compared with it for approval.

The importance of space creation and maintenance for tissue regeneration has long been recognized in regenerative dentistry. In order to prevent membrane collapse and creating the space for bone regeneration, ePTFE membranes were reinforced by titanium. Successful bone regeneration has been reported with titaniumreinforced ePTFE membranes in experimentally created supra-alveolar bone defects in dogs (11). However, the results of studies are controversial and the effectiveness of stiff membranes is debated. Zhong et al. did not find any benefit in application of titanium membranes, and interestingly, they observed that the membrane may even decrease the quantity of regenerated bone (12).

A new generation of ePTFE barrier membranes is "High Density ePTFE" membrane. These are microporous barri- ers and when placed, a complete soft tissue coverage is not necessary $(13,14)$. There are not enough controlled studies regarding these newly introduced membranes. Table 1 shows the characteristics of some available nonabsorbable membranes.

\subsection{Bioabsorbable Barrier Membranes}

Because of a need for a second surgery to remove nonabsorbable barriers, there was a demand for developing bioabsorbable membranes. Therefore, in recent years, different natural or synthetic bioabsorbable materials have been introduced. It seems that these membranes can stimulate soft tissue healing. The ability of being resorbed after exposing to the oral cavity is one of their favorable properties, since it is hypothesized that this may protect their microstructure from microbial contamination. Among these materials, collagen can be a good choice. Researchers have been always attracted by collagen due to its unique properties, which can be advantageous for regenerative treatment. Various types of collagen from different species, tissues, and organs have been used as barriers in animal and human studies (15). Low immunologic response, hemostasis promotion, chemotaxis stimulation for periodontal ligament and gingival fibroblasts, easy manipulation and ability to enhance tissue thickness in some situations are some of the advantages proposed for collagen membranes $(15,16)$. Macrophages and polymorphonuclear leukocytes will resorb this material through enzymatic activity (17).

Different microstructure and cross-linking methods have led to the production of a wide variety of collagen membranes. These parameters can alter membrane properties, including tensile strength, ease of manipulation, flexibility, tissue integrity, and biologic resorption. Cross-linking is a procedure by which the naturally-occurring links between collagen molecules are increased in order to make the membrane more resistant. It is suggested that cross-linking may cause a delay in the resorption process, and therefore, the produced material may be beneficial for complete reconstruction of larger defects. Furthermore, cross-linked collagen membranes would maintain their integrity even after exposure to the oral cavity. Nevertheless, the membrane introduction could not put an end to the hindrance of tissue regeneration since they posses some disadvantageous such as a high rate of spontaneous exposure and decrease in tissue integration and vascularity (18). Introduced techniques

\begin{tabular}{lccc}
\hline \multicolumn{4}{l}{ Table 1. Some Available Nonabsorbable Membranes and Their Characteristics } \\
$\begin{array}{l}\text { Nonabsorbable } \\
\text { Membrane }\end{array}$ & Trade Mark & Pore Size & Characteristics \\
\hline e-PTFE & Gore-Tex & $0.48 \mu \mathrm{m}$ & Gold standard material for GTR. It may be non-reinforced or titanium-reinforced. \\
d-PTFE & Cytoplast, ACE & $\begin{array}{c}\text { Less than } 0.3 \mu \mathrm{m}, \\
\text { Less than } 0.2 \mu \mathrm{m}\end{array}$ & $\begin{array}{r}\text { Membrane exposure does not influence bone regeneration. Resistant to } \\
\text { bacterial infection. It may be non-reinforced or titanium reinforced. }\end{array}$ \\
Titanium mesh & Cytoplast & Less than $0.3 \mu \mathrm{m}$ & Can be repeatedly sterilized; Inert, non-reactive \\
\hline
\end{tabular}


for cross-linking include ultraviolet light $(19,20)$, hexamethylene diisocyanate (HMDIC) (19, 21), glutaraldehyde plus irradiation (22), and diphenyl phosphoryl azide $(23,24)$. Glutaraldehyde technique, which was the most widely used chemical cross-linking technique, has been reported to leave a cytotoxic residue during the process (4). Understanding this hazardous effect made researchers to test other new techniques of cross-linking such as diphenyl phosphoryl azide (DPPA) technique (24).

Although cross-linking will postpone the resorption process, the period of time that the material acts as a barrier will not reach 4 to 6 weeks which is the substantial time that a nonresorbable membrane should stay in place before surgical removal. It has been reported that membrane stability during wound healing is necessary for volume stability of bone graft (25). Thus, the effectiveness of the collagen membrane was debated in regeneration literature because of its relatively fast resorption rate even after cross-linking. However, recently reported evidence suggested that since the epithelial proliferation occurs within the first 14 days of periodontal wound healing, it is postulated that the period of time in which a collagen membrane remains intact is sufficient to inhibit epithelial migration $(19,21)$.

Other absorbable materials such as polylactic acid and copolymers of polylactic acid and polyglycolic acid have been tested in animal and human studies and are commonly used now $(26,27)$. The mechanism of degradation of these materials in the recipient site includes hydrolysis, and they would be eliminated from the organism through the Krebs cycle as carbon dioxide and water with some potential tissue reaction during degradation. This means that, these materials are not inert, though they are biocompatible $(3,17)$. Table 2 presents characteristics of some available absorbable membranes.

\subsection{Membranes in Localized Bony Defects}

Successful bone regeneration in localized jaw defects is getting a growing desire for both patients and surgeons.
Implant emergence as a new alternative for replacing missing teeth have aroused additional concerns about the effect of ridge deficiency or insufficient bone height/ width on implant overall successfulness (15). GBR is a technique for regenerating local bony defect. However, placing bone graft or bone substitute material underneath the membrane is mandatory for achieving predictable results. While the graft functions as a scaffold and carrier for living cells, the barrier membrane is expected to fulfill the following criteria: protecting healing space, wound stabilization, blood clot preservation, decreasing bone resorption, and excluding unwanted cells and tissues $(1,15)$. It seems that membrane causes different amount of regenerated bone in defects with insufficient height and width. Vertical bone augmentation still remains a real challenge for surgeons. Many factors have been proposed by researchers for successful bone regeneration procedure, including defect size (critical or noncritical), membrane stability during healing process (28), position of the defect (maxilla or mandible) (29), preventing membrane exposure (9), and membrane thickness (single-layered or double-layered) (30). Adeyemo et al. reported that the membrane would decrease bone graft resorption provided that the membrane remains stable during healing (28). Maxillary and mandibular defects have been shown different amount of graft volume maintenance in Donos et al. study, where the mandibular defects presented less graft resorption and considerable continuity between graft and recipient site (29). Kim et al. compared double-layered and single-layered membranes and observed that double-layered membrane would decrease graft resorption and cause higher bone density (30). In spite of the fact that numerous techniques have been invented to overcome the perceived problem of bone regeneration, there is no comprehensive consensus over potential effectiveness of each technique. Attempts to find out the actual role of membranes in regenerating local bony defects have yielded to publication of many articles in this regard. In a systematic review by Khojasteh et al., they concluded that the evidence supporting the

\begin{tabular}{|c|c|c|c|}
\hline Resorbable Membrane & Trade Mark & Resorption Time & Characteristics \\
\hline \multirow[t]{3}{*}{ Collagen } & Bio-Gide & 24 weeks & $\begin{array}{c}\text { Type } 1 \text { and } 3 \text { porcine collagen, Non-cross linked, Bilayer, Type } 1 \\
\text { bovine collagen, Cross-linked Monolayer }\end{array}$ \\
\hline & Bio-Mend & 8 weeks & \\
\hline & Bio-Mend Extend & 18 weeks & \\
\hline \multirow[t]{2}{*}{ Polyglycolic acid } & Gore & 8-10 weeks & $\begin{array}{l}\text { They composed of a porous structure of synthetic bioabsorbable } \\
\text { glycolide and trimethylene carbonate copolymer fiber and an } \\
\text { occlusive membrane of synthetic bioabsorbable glycolide and } \\
\text { lactide copolymer. }\end{array}$ \\
\hline & Resolute & 16-24 weeks & \\
\hline \multirow[t]{2}{*}{ Polylactic acid } & Epi-Gide & 24-48 weeks & Three-layered design, Double-layered. \\
\hline & Guidor & 6 weeks & \\
\hline
\end{tabular}


effectiveness of membranes on human localized bony defects regeneration is not sufficient and more randomized clinical trials are needed (31).

\subsection{Membranes in Intrabony Defects}

Treating intrabony defects by barrier membranes has been developed since the first introduction of the material. In recent years, GTR got highly popular for this defect type. Bioabsorbable and nonresorbable membrane have been tested for their ability to promote regeneration in these defects. The first studies were case reports (32-35). Since then, many controlled studies have been conducted regarding the issue. Because the final outcome of the method shows some inconsistency, various membrane types and techniques of placement have been tested to overcome drawbacks of previous methods. Differences in clinical efficacy would result from some contributing factors, including membrane type, initial probing depth, and width of the defect (15). It is obvious that interfering variables such as patient's oral hygiene should be carefully controlled in clinical studies. Needleman et al. appraised available data regarding GTR effect on treating intrabony defects in a systematic review and found out that compared with open flap debridement, the method has a significant effect on improving periodontal condition, including more attachment gain and reduced pocket depth. In addition, decreased gingival recession and more gain in hard tissue probing was reported (36).

\subsection{Membranes in Furcation Defects}

The possibility of regenerating a furcation periodontal defect has been investigated for many years. The first publication was a case report by Gottlow et al. (1986). Their histologic evaluation suggested that treating the defects by GBR may result in new attachment formation (34). Since 1988, the results of several studies regarding the efficacy of GTR treatment in furcation involved teeth have been published. By screening the results, it seems that degree furcation involved mandibular molars is the only furcation defect that benefits from GTR treatment (37-39). Moreover, reports from studies published since 1988 show great variability and even controversy in clinical outcomes and some of them are not so promising. Evaluating the effectiveness of the widely used method has been the subject of a number of systematic reviews. Murphy et al. reviewed available data regarding the efficacy of GTR in periodontal osseous defect compared to surgical controls and draw the conclusion that GTR would show significant benefit when compared to open flap debridement therapies in both intrabony defects and furcation defects (40). The systematic review designed by Jepsen et al. proved GTR to be more effective than open flap debridement in reducing open horizontal furcation depths, horizontal and vertical attachment levels and pocket depths in class II furcation defects (41).

\subsection{Factors Affecting Membrane Function}

Patient's systemic condition such as diabetes, hyperparathyroidism, osteoporosis, osteomalacia, Paget's disease, and thyrotoxicosis can modulate the healing process. In addition, the quantity of autologous graft, defect size and morphology, and the number of remaining walls of the bone can change healing period (42). It is necessary to be pointed out that surgeon's experience during the surgery and precise monitoring of the wound for exposure are of great importance in all regenerative procedures.

\section{Results}

Quality of life has been affected by various bone defects for decades. Lack of healthy dentition, esthetic problems and functional complications has made clinicians to seek methods for patients' rehabilitation. Barrier membranes introduced for this purpose must have certain properties to be effective, especially in inhibiting migration of unwanted cells and to maintain space for bone regeneration. In recent years, membranes with different properties are introduced but reviewing the literature states that they all have yielded to different and even controversial results both in animal and human studies. Existence of a large number of membranes with different features and compositions can prove that none of the available membranes can result in \%100 predictable outcomes and handle bone regeneration challenge. Despite the fact that there is strong evidence supporting the theory proposed by inventors, many factors such as defect properties, patients' systemic condition, material features, utilized method and even surgeons experience can affect clinical outcome. Factors orchestrated in the tissue regeneration process should be better found out for more predictable results.

\section{Conclusions}

Many factors have been proposed for successful bone regeneration procedure with membranes, including defect size, membrane stability, position of the defect, preventing membrane exposure, and membrane thickness. Results of membranes effectiveness in treating intrabony defects were very controversial, and treating furcation defects using membranes was successful.

\section{Authors' Contributions}

Ms. Sara Soheilifar: gathering information and articles for review and reviewing the articles; Mr. Mohsen Bidgoli: gathering the information and reviewing the articles; Mr. Parviz Tokzaban: reviewing the articles; and Ms. Sepideh Soheilifar: reviewing the articles and writing this review article and submitting it.

\section{References}

1. Gielkens PF, Bos RR, Raghoebar GM, Stegenga B. Is there evidence that barrier membranes prevent bone resorption in autologous 
Soheilifar S et al.

bone grafts during the healing period? A systematic review. Int $J$ Oral Maxillofac Implants. 2007;22(3):390-8.

2. Paderni S, Terzi S, Amendola L. Major bone defect treatment with an osteoconductive bone substitute. Chir Organi Mov. 2009;93(2):89-96.

3. Garrett S. Periodontal regeneration around natural teeth. Ann Periodontol. 1996;1(1):621-66.

4. American Academy of Periodontology . Glossary of periodontal terms.Chicago:American Academy of Periodontology; 1992.p. 42.

5. Hollinger JO, Buck DC, Bruder SP. Biology of bone healing: Its impact on clinical therapy. In: Lynch SE, Genco RJ, Marx RE, editors. issue Engineering.Applications in Maxillofacial Surgery and Periodontics.. Chicago: Quintessence;1999. pp. 17-53.

6. Lindhe J, Lang NP, Karring T. Clinical Periodontology and Implant Dentistry.: Wiley; 2009.

7. Gottlow J, Nyman S, Karring T, Lindhe J. New attachment formation as the result of controlled tissue regeneration. J Clin Periodontol. 1984;11(8):494-503.

8. Cosyn J, De Bruyn H. [Guided bone regeneration: general survey]. Rev Belge Med Dent (1984). 2009;64(4):160-72.

9. Donos N, Kostopoulos L, Karring T. Alveolar ridge augmentation by combining autogenous mandibular bone grafts and nonresorbable membranes. Clin Oral Implants Res. 2002;13(2):185-91.

10. Rasmusson L, Meredith N, Kahnberg KE, Sennerby L. Effects of barrier membranes on bone resorption and implant stability in onlay bone grafts. An experimental study. Clin Oral Implants Res. 1999;10(4):267-77.

11. Newman MG, Takei H, Klokkevold PR, Carranza FA. Carranza's Clinical Periodontology. 10th ed. Philadelphia: Elsevier Health Sciences; 2006.

12. Zhong W, Ma G, Wang Y, Tamamura R, Xiao J. Augmentation of Peri-implant Bone Defects with Different Bone Grafts and Guided Bone Regeneration: A Pilot Experimental Study in the Dog.J Hard Tissue Biol. 2006;15(3):82-8.

13. Barber HD, Lignelli J, Smith BM, Bartee BK. Using a dense PTFE membrane without primary closure to achieve bone and tissue regeneration.J Oral Maxillofac Surg. 2007;65(4):748-52.

14. Marouf HA, El-Guindi HM. Efficacy of high-density versus semipermeable PTFE membranes in an elderly experimental model. Oral Surg Oral Med Oral Pathol Oral Radiol Endod. 2000; 89(2):164-70.

15. Bunyaratavej P, Wang HL. Collagen membranes: a review. J Periodontol. 2001;72(2):215-29.

16. Locci P, Calvitti M, Belcastro S, Pugliese M, Guerra M, Marinucci L, et al. Phenotype expression of gingival fibroblasts cultured on membranes used in guided tissue regeneration. J Periodontol. 1997;68(9):857-63.

17. Tatakis DN, Promsudthi A, Wikesjo UM. Devices for periodontal regeneration. Periodontol 2000.1999;19:59-73.

18. Moses O, Vitrial D, Aboodi G, Sculean A, Tal H, Kozlovsky A, et al. Biodegradation of three different collagen membranes in the rat calvarium: a comparative study. J Periodontol. 2008;79(5):905-11.

19. Minabe M, Kodama T, Kogou T, Tamura T, Hori T, Watanabe Y, et al Different cross-linked types of collagen implanted in rat palatal gingiva. J Periodontol.1989;60(1):35-43.

20. Pitaru S, Tal H, Soldinger M, Grosskopf A, Noff M. Partial regeneration of periodontal tissues using collagen barriers. Initial observations in the canine. J Periodontol.1988;59(6):380-6.

21. Kodama T, Minabe M, Hori T, Watanabe Y. The effect of various concentrations of collagen barrier on periodontal wound healing.J Periodontol. 1989;60(4):205-10.

22. Quteish D, Dolby AE. The use of irradiated-crosslinked human collagen membrane in guided tissue regeneration. J Clin Periodontol. 1992;19(7):476-84.

23. Brunel G, Piantoni P, Elharar F, Benque E, Marin P, Zahedi S. Regeneration of rat calvarial defects using a bioabsorbable membrane technique: influence of collagen cross-linking. J Periodontol.1996;67(12):1342-8.
24. Zahedi S, Legrand R, Brunel G, Albert A, Dewe W, Coumans B, et al. Evaluation of a diphenylphosphorylazide-crosslinked collagen membrane for guided bone regeneration in mandibular defects in rats.J Periodontol.1998;69(11):1238-46.

25. Blumenthal NM. The use of collagen membranes to guide regeneration of new connective tissue attachment in dogs. J Periodontol.1988;59(12):830-6.

26. Hurzeler MB, Quinones CR, Caffesse RG, Schupbach P, Morrison EC. Guided periodontal tissue regeneration in interproximal intrabony defects following treatment with a synthetic bioabsorbable barrier.J Periodontol.1997;68(5):489-97.

27. Sculean A, Donos N, Chiantella GC, Windisch P, Reich E, Brecx $M$. GTR with bioresorbable membranes in the treatment of intrabony defects: a clinical and histologic study. Int J Periodontics Restorative Dent.1999;19(5):501-9.

28. Adeyemo WL, Reuther T, Bloch W, Korkmaz Y, Fischer JH, Zoller JE, et al. Healing of onlay mandibular bone grafts covered with collagen membrane or bovine bone substitutes: a microscopical and immunohistochemical study in the sheep. Int J Oral Maxillofac Surg. 2008;37(7):651-9.

29. Donos N, Kostopoulos L, Karring T. Augmentation of the rat jaw with autogeneic cortico-cancellous bone grafts and guided tissue regeneration. Clin Oral Implants Res. 2002;13(2):192-202.

30. Kim SH, Kim DY, Kim KH, Ku Y, Rhyu IC, Lee YM. The efficacy of a double-layer collagen membrane technique for overlaying block grafts in a rabbit calvarium model. Clin Oral Implants Res. 2009;20(10):1124-32.

31. Khojasteh A, Soheilifar S, Mohajerani H, Nowzari H. The effectiveness of barrier membranes on bone regeneration in localized bony defects: a systematic review. Int J Oral Maxillofac Implants. 2013;28(4):1076-89.

32. Becker W, Becker BE, Berg L, Prichard J, Caffesse R, Rosenberg E. New attachment after treatment with root isolation procedures: report for treated Class III and Class II furcations and vertical osseous defects. Int J Periodontics Restorative Dent. 1988;8(3):8-23.

33. Cortellini P, Pini Prato G, Baldi C, Clauser C. Guided tissue regeneration with different materials. Int J Periodontics Restorative Dent. 1990;10(2):136-51.

34. Gottlow J, Nyman S, Lindhe J, Karring T, Wennstrom J. New attachment formation in the human periodontium by guided tissue regeneration. Case reports. J Clin Periodontol.1986;13(6):604-16.

35. Nyman S, Lindhe J, Karring T, Rylander H. New attachment following surgical treatment of human periodontal disease. J Clin Periodontol.1982;9(4):290-6.

36. Needleman IG, Worthington HV, Giedrys-Leeper E, Tucker RJ Guided tissue regeneration for periodontal infra-bony defects. Cochrane Database Syst Rev. 2006(2):CD0 01724.

37. Caffesse RG, S. Mith BA, Duff B, Morrison EC, Merrill D, Becker W. Class II furcations treated by guided tissue regeneration in humans: case reports. J Periodontol. 1990;61(8):510-4.

38. Lekovic V, Kenney EB, Kovacevic K, Carranza FA, Jr. Evaluation of guided tissue regeneration in Class II furcation defects. A clinical re-entry study.J Periodontol.1989;60(12):694-8.

39. Pontoriero R, Lindhe J, Nyman S, Karring T, Rosenberg E, Sanavi F. Guided tissue regeneration in the treatment of furcation defects in mandibular molars. A clinical study of degree III involvements. J Clin Periodontol.1989;16(3):170-4.

40. Murphy KG, Gunsolley JC. Guided tissue regeneration for the treatment of periodontal intrabony and furcation defects. A systematic review. Ann Periodontol. 2003;8(1):266-302.

41. Jepsen S, Eberhard J, Herrera D, Needleman I. A systematic review of guided tissue regeneration for periodontal furcation defects. What is the effect of guided tissue regeneration compared with surgical debridement in the treatment of furcation defects? J Clin Periodontol. 2002;29 Suppl 3:103-16.

42. El Helow K, El Askary Ael S. Regenerative barriers in immediate implant placement: a literature review. Implant Dent. 2008;17(3):360-71. 